\title{
Analisis Survival Model Regresi Parametrik Lama Studi Mahasiswa
}

\author{
Novita Eka Chandra \\ Program Studi Mtematika FMIPA Universitas Islam Darul Ulum Lamongan \\ novitaeka@unisda.ac.id \\ Siti Alfiatur Rohmaniah \\ Program Studi Matematika FMIPA Universitas Islam Darul Ulum Lamongan \\ nia0304@gmail.com
}

\begin{abstract}
Timely graduation of students can be used as an indicator to show the quality of a university. Students are said to graduate on time if they have a short study period of 4 years. The duration of the study of students varies because it is influenced by several factors. The purpose of this study is to determine the factors that have a significant effect on the duration of student studies. The factors studied included gender, GPA, school origin, joining the organization and working in college. The method used in this study is survival analysis. Survival analysis in this study used Log-normal and Weibull, parametric regression models. From the two models, it was found that the GPA and organizational factors significantly influence the duration of student studies. The selection of the best model is determined based on the minimum AIC value. Based on the comparison of the two models, the parametric Weibull model has a minimum AIC value, so this model is the best model. Based on $H R$ values, students who have a higher GPA and are more active tend to graduate faster or having lower duration of studies.
\end{abstract}

Keywords: survival, regression, parametric, time of study.

\section{Pendahuluan}

Salah satu indikator keberhasilan suatu universitas dapat dilihat dari ketepatan waktu lulus mahasiswa. Berdasarkan Peraturan Menristek Dikti tahun 2015, lama studi untuk mahasiswa sarjana maksimum 7 tahun. Apabila lama studi mahasiswa melewati batas maksimum akan dilakukan drop out. Oleh karena itu, mahasiswa diharapkan dapat lulus tepat waktu paling tidak 4 tahun lama studi. Menurut hasil pengamatan di lapangan, masih ada beberapa mahasiswa yang belum lulus studi dengan lama studi 4 tahun. Hal ini akan berdampak buruk pada kualitas dari universitas itu sendiri. Lama studi mahasiswa terhitung dari awal pertama kali kuliah hingga dinyatakan lulus sebagai sarjana. Lama studi setiap mahasiswa berbeda-beda, hal ini disebabkan oleh 
beberapa faktor. Hutahaean, et al (2014) melakukan penelitian mengenai lama studi mahasiswa dengan menggunakan model regresi parametrik Cox Proportional Hazard, dari hasil penelitian tersebut diperoleh bahwa lama studi dipengaruhi oleh jurusan, Indeks Prestasi Kumulatif (IPK), dan organisasi. Hal serupa juga dilakukan oleh Astutik dan Tresnawan (2017) yang mengimplementasikan model regresi parametrik Cox Proportional Hazard pada analisis survival data lama studi mahasiswa. Berdasarkan data pengamatan, mahasiswa yang memiliki gender perempuan lebih cenderung lebih cepat lama studinya dibandingkan mahasiswa laki-laki, dan lebih banyak mahasiswa yang lulus berasal dari SMA. Selain kuliah, beberapa mahasiswa juga memiliki kesibukan tersendiri seperti mengikuti organisasi dan bekerja. Apabila mahasiswa tidak dapat mengatur wakktu antara kuliah dan kesibukannya tersebut akan berdampak pada lama studinya. Dengan begitu, faktor-faktor yang akan diteliti dalam penelitian ini, diantaranya gender, IPK, asal sekolah, mengikuti organisasi dan bekerja. Untuk menentukan faktor-faktor yang berpengaruh secara signifikan diperlukan adanya analisis survival. Menurut Collet (2015), analisis survival digunakan untuk menggambarkan analisis data dalam bentuk waktu dari awal waktu dilakukannya pengamatan sampai terjadinya suatu peristiwa tertentu. Waktu sampai terjadinya suatu peristiwa sering dikenal dengan waktu survival (Kleinbaum \& Klein, 2010). Analisis survival dalam penelitian ini menggunakan model survival parametrik yaitu model regresi parametrik, dimana parametrik disini adalah banyaknya parameter dalam model regresi berhingga banyak (Danardono, 2012). Lebih lanjut, model survival parametrik adalah model yang waktu survivalnya diasumsikan mengikuti suatu distribusi yang diketahui (Harlan, 2017), sedangkan regresi merupakan suatu metode yang digunakan untuk menentukan pengaruh variabel independen terhadap variabel dependen (waktu survival). Model regresi parametrik seringkali menggunakan asumsi waktu survival mengikuti distribusi Weibull, Eksponensial, Logistik, dan lain sebagainya (Zhang, 2016) (Rohmaniah \& Danardono, 2016) (Sudrajat, Rizki, \& Perdana, 2018).

Selain untuk menentukan faktor yang berpengaruh signifikan, penelitian ini juga bertujuan untuk menentukan model yang terbaik berdasarkan nilai AIC (Akaike's Information Criterion) (Moore, 2016). Dari hasil penelitian ini diharapkan dapat digunakan untuk menentukan peluang mahasiswa lulus tepat waktu, sehingga dapat digunakan untuk meningkatkan kualitas universitas.

\section{Metode Penelitian}

Analisis survival sangat memperhatikan penyensoran data. Menurut Kleinbaum \& Klein (2010), data tersensor terjadi jika :

a. Objek tidak mengalami peristiwa sebelum pengamatan berakhir

b. Objek menghilang selama pengamatan berlangsung 
c. Objek individu terpaksa dihentikan karena kematian atau disebabkan alasan lain. Pada analisis survival penyensoran data terdiri dari sensor kanan, sensor kiri, dan sensor interval. Data dikatakan tersensor kanan jika waktu survivalnya melebihi waktu survival pengamatan, tersensor kiri terjadi jika waktu survivalnya kurang dari waktu survival pengamatan, dan sensor interval terjadi jika waktu survivalnya berada pada waktu survival yang diamati.

Model parametrik survival adalah model dengan waktu survival diasumsikan mengikuti suatu distribusi yang diketahui, seperti distribusi Weibull, Eksponensial, Log-logistik, Log-normal dan Gamma (Kleinbaum \& Klein, 2010). Bentuk dasar model AFT regresi parametrik survival yaitu (Danardono, 2012):

$$
S(t \mid \psi)=S_{0}(\psi t)
$$

dengan $\psi(\mathbf{X} ; \boldsymbol{\theta})=\beta_{0}+\beta_{1} x_{1}+\beta_{2} x_{2}+\ldots+\beta_{p} x_{p}$ dan $S_{0}(t)$ adalah baseline survival.

Distribusi Weibull dengan parameter bentuk $\alpha>0$ dan skala $\lambda>0$ mempunyai fungsi survival

$$
S(t)=\exp \left(-(\lambda t)^{\alpha}\right) .
$$

Dengan demikian, bentuk model regresi survival Weibull sebagai berikut :

$$
\begin{aligned}
& S(t \mid \psi)=\exp \left(-(\lambda \psi t)^{\alpha}\right) \\
& S(t \mid \mathbf{X})=\exp \left(-\left(\exp (\mathbf{X} \boldsymbol{\beta} t)^{\alpha}\right)\right.
\end{aligned}
$$

dengan $\lambda=\exp (\mathbf{X} \boldsymbol{\beta})$.

Variabel independen $\mathbf{X}$ dalam model regresi Log-normal memodifikasi fungsi survival $S(t)=1-\Phi\left(\frac{\log (t)-\mu}{\sigma}\right)$ melalui parameter $\mu(\mathbf{X})=\mathbf{X} \boldsymbol{\beta}$, menjadi

$$
S(t)=1-\Phi\left(\frac{\log (t)-\mathbf{X} \boldsymbol{\beta}}{\sigma}\right)
$$

dengan $\Phi(x)$ adalah fungsi distribusi kumulatif Normal Standar. Dengan begitu, bentuk model regresi Log-normal sebagai berikut :

$$
S(t \mid \psi)=1-\Phi\left(\frac{\log (\psi t)-\mathbf{X} \boldsymbol{\beta}}{\sigma}\right) .
$$

Selanjutnya, untuk mendapatkan informasi mengenai resiko kegagalan digunakan nilai Hazard Ratio (HR). Nilai HR merupakan perbandingan nilai hazard individu satu dengan nilai hazard individu yang berbeda. Perbandingan keduas individu tersebut dapat dibedakan untuk setiap variabel independen $X$. Nilai HR dapat ditulis dengan

$$
H R=\frac{\hat{h}\left(t \mid X^{*}\right)}{\hat{h}(t \mid X)}=\exp \left[\sum_{i=1}^{p} \beta_{i}\left(X_{i}^{*}-X_{i}\right)\right]
$$


dengan $\hat{h}\left(t \mid X^{*}\right)$ merupakan estimasi hazard dari variabel independen individu satu dan $\hat{h}\left(t \mid X^{*}\right)$ merupakan estimasi hazard dari variabel individu yang berbeda.

Data yang digunakan dalam penelitian ini yaitu data lama studi dari 838 mahasiswa angkatan 2014 di Universitas Islam Darul Ulum Lamongan baik yang sudah lulus maupun belum lulus sampai Februari 2019. Data ini diperoleh secara langsung melalui kuisioner maupun secara tidak langsung yang diambil dari Biro Administrasi Akademik dan Kepegawaian Universitas Islam Darul Ulum Lamongan. Data tersebut meliputi lama studi (sebagai waktu survival dengan satuan bulan), status (lulus dan belum lulus), gender (laki-laki dan perempuan), IPK, asal sekolah (SMA, MA dan SMK), organisasi (mengikuti atau tidak), serta bekerja saat kuliah atau tidak. Analisis data menggunakan metode analisis survival regresi parametrik dengan bantuan software R 3.52. Adapun tahapan yang dilakukan pada penelitian ini sebagai berikut :

a. Melakukan analisis deskriptif data

b. Menentukan data lama studi mengikuti distribusi tertentu

c. Melakukan analisis survival model regresi Weibull dan menentukan faktor yang berpengaruh signifikan terhadap lama studi mahasiswa

d. Melakukan analisis survival model regresi Log-logistik dan menentukan faktor yang berpengaruh signifikan terhadap lama studi mahasiswa

e. Melakukan analisis survival model regresi Log-normal dan menentukan faktor yang berpengaruh signifikan terhadap lama studi mahasiswa

f. Membandingkan dan menentukan model terbaik dari ketiga model regresi survival dengan melihat nilai AIC paling minimum

g. Menentukan Hazard Ratio (HR) lama studi mahasiswa.

\section{Hasil dan Pembahasan}

\subsection{Analisis Statistika Deskriptif}

Pada bagian ini dipaparkan hasil dari statistika deskriptif dari data survival. Data survival yang digunakan terdiri dari data kategori dan data numerik. Untuk data kategori yaitu variabel gender, asal sekolah, organisasi dan bekerja, sedangkan data numerik terdiri dari variabel lama studi dan IPK. Untuk variabel status dikategorikan menjadi dua yaitu status tersensor dan status terobservasi. Status tersensor untuk mahasiswa yang dinyatakan belum lulus dan tidak melanjutkan kuliah sampai Februari 2019, sedangkan status terobservasi untuk mahasiswa yang dinyatakan telah lulus studi. Berikut hasil outputnya.

Tabel 1. Gender Berdasarkan Status

\begin{tabular}{|c|c|c|}
\hline Variabel & Status & Total \\
\hline
\end{tabular}




\begin{tabular}{|c|c|c|c|c|}
\hline \multicolumn{2}{|c|}{} & Tersensor & Terobservasi & \\
\hline \multirow{3}{*}{ Gender } & Laki-laki & 201 & 156 & 357 \\
\cline { 2 - 5 } & Perempuan & 148 & 333 & 481 \\
\hline \multicolumn{2}{|c|}{ Total } & 349 & 489 & 838 \\
\hline
\end{tabular}

Terlihat pada Tabel 1 mahasiswa perempuan lebih banyak dibandingkan mahasiswa laki-laki, karena terdapat 42,6\% mahasiswa laki-laki dan 57,4\% mahasiswa perempuan. Dari total mahasiswa, yang telah lulus sebesar 58,4\% yang terdiri dari $68 \%$ perempuan dan $32 \%$ laki-laki, sebaliknya yang belum lulus sebanyak $41,6 \%$ yang terdiri dari $57,6 \%$ laki-laki dan 42,4\% perempuan. Dapat disimpulkan bahwa mahasiswa perempuan lebih banyak yang lulus daripada mahasiswa laki-laki.

Tabel 2. Asal Sekolah Berdasarkan Status

\begin{tabular}{|c|c|c|c|c|}
\hline \multirow{2}{*}{\multicolumn{2}{|c|}{ Variabel }} & \multicolumn{2}{|c|}{ Status } & \multirow{3}{*}{\begin{tabular}{|l} 
Total \\
299
\end{tabular}} \\
\hline & & Tersensor & Terobservasi & \\
\hline \multirow{3}{*}{$\begin{array}{l}\text { Asal } \\
\text { sekolah }\end{array}$} & SMA & 110 & 189 & \\
\hline & MA & 136 & 172 & 308 \\
\hline & SMK & 103 & 128 & 231 \\
\hline \multicolumn{2}{|c|}{ Total } & 349 & 489 & 838 \\
\hline
\end{tabular}

Terlihat pada Tabel 2 mahasiswa yang berasal dari lulusan MA lebih banyak dibandingkan dari SMA dan SMK. Terdapat 58,4\% mahasiswa telah lulus didominasi oleh mahasiswa yang berasal dari SMA, sebaliknya sisanya $41,6 \%$ belum dinyatakan lulus studi.

Tabel 3. Organisasi Berdasarkan Status

\begin{tabular}{|c|c|c|c|c|}
\hline \multirow{2}{*}{\multicolumn{2}{|c|}{ Variabel }} & \multicolumn{2}{|c|}{$\begin{array}{c}\text { Status } \\
\end{array}$} & \multirow{3}{*}{$\begin{array}{c}\text { Total } \\
392 \\
\end{array}$} \\
\hline & & \multirow{2}{*}{$\begin{array}{c}\text { Tersensor } \\
134 \\
\end{array}$} & \multirow{2}{*}{$\begin{array}{c}\text { Terobservasi } \\
258 \\
\end{array}$} & \\
\hline Organisasi & Ya & & & \\
\hline & Tidak & 215 & 231 & 446 \\
\hline \multicolumn{2}{|c|}{ Total } & 349 & 489 & 838 \\
\hline
\end{tabular}

Pada Tabel 3 terlihat bahwa lebih sedikit mahasiswa yang mengikuti organisasi daripada yang tidak mengikuti organisasi saat menempuh studi. Untuk mahasiswa yang telah lulus, ada 52,7\% yang mengikuti organisasi saat studi. Sebaliknya, terdapat 38,4\% mahasiswa yang mengikuti organisasi tetapi belum lulus studi.

Tabel 4. Bekerja Berdasarkan Status

\begin{tabular}{|c|c|c|c|c|}
\hline \multirow{2}{*}{\multicolumn{2}{|c|}{ Variabel }} & \multicolumn{2}{|c|}{ Status } & \multirow{3}{*}{\begin{tabular}{|l|} 
Total \\
412 \\
\end{tabular}} \\
\hline & & \multirow{2}{*}{$\begin{array}{c}\text { Tersensor } \\
185\end{array}$} & \multirow{2}{*}{$\begin{array}{c}\text { Terobservasi } \\
227\end{array}$} & \\
\hline Bekerja & Ya & & & \\
\hline & Tidak & 164 & 262 & 426 \\
\hline \multicolumn{2}{|c|}{ Total } & 349 & 489 & 838 \\
\hline
\end{tabular}


Berdasarkan hasil pada Tabel 4, mahasiswa yang bekerja dan tidak saat menempuh studi memiliki perbedaan sebesar $1,7 \%$, dalam hal ini lebih banyak mahasiswa yang tidak bekerja. Lebih lanjut, terlihat bahwa mahasiswa yang bekerja yang telah lulus lebih banyak 10,2\% dibandingkan yang belum lulus tetapi bekerja.

Tabel 5. Statistika Deskriptif Lama Studi dan IPK

\begin{tabular}{|l|c|c|c|c|c|}
\hline Variabel & Min & Mean & Median & Modus & Maks \\
\hline Lama studi & 47 & 50,3 & 48 & 54 & 54 \\
\hline IPK & 2,6 & 3,3427 & 3,33 & 3,01 & 3,97 \\
\hline
\end{tabular}

Terlihat pada Tabel 5, rata-rata nilai IPK mahasiswa sebesar 3,3427 dengan nilai IPK terkecil 2,6 dan terbesar 3,97. Untuk lama studi paling cepat mahasiswa menempuh studi selama 47 bulan.

\subsection{Penentuan Distribusi}

Tahap selanjutnya menentukan distribusi dari data waktu survival, yaitu lama studi mahasiswa. Untuk menentukan jenis distribusi dari data dilihat berdasarkan nilai AIC terkecil. Perhatikan hasil output di bawah ini.

Tabel 6. Nilai AIC Lama Studi dengan Distribusi Berbeda

\begin{tabular}{|c|c|}
\hline Distribusi & Nilai AIC \\
\hline Eksponensial & 8244,6 \\
\hline Rayleigh & 7092,674 \\
\hline Logistik & 4420,877 \\
\hline Log-logistik & 4404,222 \\
\hline Ekstrim & 4382,025 \\
\hline Weibull & 4364,477 \\
\hline Log-normal & 4286,694 \\
\hline
\end{tabular}

Terlihat pada Tabel 6, ada dua distribusi yang memiliki nilai AIC terkecil yaitu distribusi Log-normal dan Weibull. Kedua distribusi tersebut yang digunakan untuk menentukan faktor-faktor yang mempengaruhi lama studi mahasiswa.

\subsection{Analisis Survival Model Regresi Log-normal}

Hasil estimasi model regresi Log-normal menggunakan software R 3.5.2 sebagai berikut :

Tabel 7. Estimasi Parameter Awal Model Regresi Log-normal

\begin{tabular}{|l|l|l|l|l|}
\hline \multicolumn{1}{|c|}{ Variabel } & Koefisien & \multicolumn{1}{c|}{ Standar Error } & \multicolumn{1}{c|}{ P-value } & \multicolumn{1}{c|}{ Keputusan } \\
\hline Intersep & 4,72413 & 0,03191 & $<2 \mathrm{e}-16$ & \\
\hline Gender_2 & 0,00267 & 0,00520 & 0,6084 & Tidak mempengaruhi \\
\hline IPK & $-0,23471$ & 0,00945 & $<2 \mathrm{e}-16$ & Mempengaruhi \\
\hline Asal sekolah_2 & 0,01640 & 0,00544 & 0,0026 & Mempengaruhi \\
\hline Asal sekolah_3 & $-0,00449$ & 0,00594 & 0,4499 & Tidak mempengaruhi \\
\hline
\end{tabular}




\begin{tabular}{|l|l|l|l|l|}
\hline Organisasi_1 & $-0,01499$ & 0,00470 & 0,0014 & Tidak mempengaruhi \\
\hline Bekerja_1 & 0,00154 & 0,00477 & 0,7467 & Tidak mempengaruhi \\
\hline $\begin{array}{l}\text { Scale }=0,0603 \\
\text { Chiq }=686,39 \quad \text { p-value }=5,3 e-145\end{array}$
\end{tabular}

Terlihat pada Tabel 7 variabel gender, asal sekolah dan bekerja memiliki nilai p-value lebih besar dari 0,05, artinya variabel gender_2, asal sekolah_3, organisasi_1, dan bekerja_1 tidak mempengaruhi lama studi secara signifikan. Sebaliknya, variabel IPK dan asal sekolah_2 memiliki p-value lebih kecil dari 0,05, artinya variabel IPK dan asal sekolah_2 berpengaruh secara signifikan terhadap lama studi mahasiswa. Karena masih terdapat varibel yang tidak signifikan, maka variabel tersebut dikeluarkan secara bertahap melalui eliminasi backward. Setelah dilakukan analisis ulang diperoleh hasil estimasi terbaik dari model regresi Log-normal berikut :

Tabel 8. Estimasi Parameter Akhir Model Regresi Log-normal

\begin{tabular}{|l|l|l|l|l|}
\hline \multicolumn{1}{|c|}{ Variabel } & \multicolumn{1}{c|}{ Koefisien } & \multicolumn{1}{c|}{ Standar Error } & \multicolumn{1}{c|}{ P-value } & Keputusan \\
\hline Intersep & 4,71860 & 0,03030 & $<2 \mathrm{e}-16$ & \\
\hline IPK & $-0,23097$ & 0,00877 & $<2 \mathrm{e}-16$ & Mempengaruhi \\
\hline Organisasi_1 & $-0,01480$ & 0,00466 & 0,0015 & Mempengaruhi \\
\hline $\begin{array}{l}\text { Scale }=0,0609 \\
\text { Chiq }=671,41\end{array}$ p-value $=1,6 \mathrm{e}-146$ \\
\hline
\end{tabular}

Berdasarkan hasil pengujian signifikansi parameter secara parsial pada Tabel 8, variabel IPK dan organisasi_1 telah signifikan terhadap lama studi mahasiswa. Hal ini terlihat dari nilai p-value yang kurang dari 0,05. Secara keseluruhan, model regresi telah signifikan dan layak digunakan, karena p-value 1,6e-146 lebih kecil dari 0,05.

\subsection{Analisis Survival Model Regresi Weibull}

Hasil estimasi model regresi Weibull menggunakan software R 3.5.2 sebagai berikut :

Tabel 9. Estimasi Parameter Awal Model Regresi Weibull

\begin{tabular}{|c|c|c|c|c|}
\hline Variabel & Koefisien & Standar Error & P-value & Keputusan \\
\hline Intersep & 4,83 & 0,0282 & $<2 \mathrm{e}-16$ & \\
\hline Gender_2 & $-1,82 \mathrm{e}-3$ & $4,83 e-3$ & 0,7062 & Tidak mempengaruhi \\
\hline IPK & $-0,26$ & $8,31 \mathrm{e}-3$ & $<2 \mathrm{e}-16$ & Mempengaruhi \\
\hline Asal sekolah_2 & 0,0189 & $4,85 \mathrm{e}-3$ & 0,0001 & Mempengaruhi \\
\hline Asal sekolah_3 & $3,33 e-5$ & $5,37 e-3$ & 0,9951 & Tidak mempengaruhi \\
\hline Organisasi_1 & $-7,39 \mathrm{e}-3$ & $4,27 \mathrm{e}-3$ & 0,0836 & Tidak mempengaruhi \\
\hline Bekerja_1 & $4,03 e-3$ & $4,29 \mathrm{e}-3$ & 0,3484 & Tidak mempengaruhi \\
\hline $\begin{array}{l}\text { Scale }=0,0453 \\
\text { Chiq }=924,02\end{array}$ & $\mathrm{ue}=2,4 \mathrm{e}-$ & & & \\
\hline
\end{tabular}


Terlihat pada Tabel 9 variabel gender, asal sekolah dan bekerja memiliki nilai p-value lebih besar dari 0,05, artinya variabel gender_1, asal sekolah_3, organisasi_1, dan bekerja_1 tidak mempengaruhi lama studi secara signifikan. Sebaliknya, variabel IPK dan organisasi memiliki p-value lebih kecil dari 0,05, artinya variabel IPK dan asal sekolah_2 berpengaruh secara signifikan terhadap lama studi mahasiswa. Karena masih terdapat varibel yang tidak signifikan, maka variabel tersebut dikeluarkan secara bertahap melalui eliminasi backward. Setelah dilakukan analisis ulang diperoleh hasil estimasi terbaik dari model regresi Weibull berikut :

Tabel 10. Estimasi Parameter Akhir Model Regresi Weibull

\begin{tabular}{|c|c|c|c|c|}
\hline Variabel & Koefisien & Standar Error & P-value & Keputusan \\
\hline Intersep & 4,83210 & 0,02702 & $<2 \mathrm{e}-16$ & \\
\hline IPK & $-0,25826$ & 0,00766 & $<2 \mathrm{e}-16$ & Mempengaruhi \\
\hline Organisasi_1 & $-0,00875$ & 0,00422 & 0,038 & Mempengaruhi \\
\hline \multicolumn{5}{|l|}{ Scale $=0,0459$} \\
\hline
\end{tabular}

Berdasarkan hasil pengujian signifikansi parameter secara parsial pada Tabel 10, variabel IPK dan organisasi_1 telah signifikan terhadap lama studi mahasiswa. Hal ini terlihat dari nilai p-value yang kurang dari 0,05. Secara keseluruhan, model regresi telah signifikan dan layak digunakan, karena p-value 3e-197 lebih kecil dari 0,05.

\subsection{Penentuan Model Terbaik}

Tahap selanjutnya yaitu pemilihan model terbaik antara model regresi survival Log-normal dengan Weibull. Pemilihan model terbaik ini berdasarkan nilai AIC minimum. Berikut perbandingan kedua model regresi.

Tabel 11. Perbandingan Estimasi Parameter

\begin{tabular}{|l|l|l|}
\hline Model Regresi Survival & Variabel Signifikan & Nilai AIC \\
\hline Log-normal & IPK dan organisasi & 2861,266 \\
\hline Weibull & IPK dan organisasi & 2827,221 \\
\hline
\end{tabular}

Berdasarkan Tabel 11 nilai AIC untuk model regresi survival Weibull lebih kecil dibandingkan model regresi survival Log-normal. Dengan demikian, dapat dikatakan bahwa model regresi survival Weibull lebih baik untuk menentukan faktor-faktor yang berpengaruh secara signifikan terhadap lama studi mahasiswa. Dengan begitu, faktor yang berpengaruh secara signifikan yaitu IPK dan organisasi, sehingga model regresi survival terbaik dapat ditulis dengan

$$
\left.S(t \mid X)=\exp \left(-\exp \left(4,83210-0,25826 X_{I P K}-0,00875 X_{\text {Organisasi_1 }_{1}}\right) t\right)^{\alpha}\right) .
$$

Untuk model Weibull diperoleh nilai estimasi untuk $\alpha$ yaitu $\hat{\alpha}=0,0459$. Selanjutnya dilakukan perhitungan nilai HR. Nilai HR atau Hazard Ratio merupakan besarnya rasio resiko kegagalan dari individu dengan kondisi variabel indepen- 
den pada kategori sukses dan kategori gagal. Nilai HR digunakan untuk melihat resiko kegagalan lama studi mahasiswa lulus tepat waktu.

a. Apabila diambil nilai IPK 3,75 (cumlaude) dan 3,25 (tidak cumlaude), maka diperoleh nilai HR sebagai berikut :

$$
\begin{aligned}
H R & =\frac{\exp (\operatorname{coef}(3,75))}{\exp (\operatorname{coef}(3,25))} \\
& =\frac{\exp (0,25826(3,75))}{\exp (0,25826(3,25))} \\
& =1,14 .
\end{aligned}
$$

Artinya, mahasiswa yang memiliki nilai IPK 3,75 laju lama studinya 1,14 bulan lebih cepat dibandingkan mahasiswa yang memiliki IPK 3,25. Dengan begitu, dapat dikatakan bahwa mahasiswa yang memiliki IPK lebih tinggi lebih cepat lama studinya dibandingkan mahasiswa yang memiliki IPK rendah.

b. Mahasiswa yang mengikuti organisasi akan memiliki nilai HR sebesar

$$
\begin{aligned}
H R & =\frac{\exp (\operatorname{coef}(1))}{\exp (\operatorname{coef}(0))} \\
& =\frac{\exp (0,00875(1))}{\exp (0,00875(0))} \\
& =0,99 .
\end{aligned}
$$

Karena 0,99 kurang dari 1 , artinya mahasiswa yang aktif mengikuti organisasi lama studinya lebih lama dibandingkan mahasiswa yang tidak aktif organisasi.

\section{Kesimpulan dan Saran}

Berdasarkan hasil dan pembahasan yang telah dilakukan, diperoleh kesimpulan bahwa model regresi survival Weibull merupakan model terbaik untuk menganalisis lama studi mahasiswa. Adapun faktor-faktor yang mempengaruhi lama studi mahasiswa yaitu IPK dan organisasi. Mahasiswa yang memiliki IPK lebih tinggi dan tidak aktif berorganisasi lebih cepat lulus atau dapat dikatakan memiliki lama studi yang lebih sedikit. Oleh karenanya, penelitian ini diharapkan dapat digunakan sebagai acuan untuk meningkatkan kualitas universitas melalui peningkatan nilai IPK mahasiswa dan keaktifan mahasiswa.

\section{Ucapan Terima Kasih}


Penulis mengucapkan terima kasih kepada DRPM Kemenristek Dikti yang telah membiayai penelitian ini melalui dana Hibah Penelitian Dosen Pemula tahun anggaran 2019.

\section{Daftar Pustaka}

Astuti, Y. S., \& Tresnawan, D. (2017). Implementasi Cox Proportional Hazard Model Parametrik Pada Analisis Survival (Studi Kasus: Mahasiswa Universitas Internasional Batam). Unisda Journal of Mathematics and Computer Science (UJMC), 3(1), 29-38.

Collett, D. (2015). Modelling Survival Data in Medical Research. Chapman and Hall/CRC.

Danardono, D. (2012). Analisis Data Survival. Yogyakarta: Universitas Gadjah Mada.

Harlan, J. (2017). Analisis Survival. Depok: Gunadarma.

Hutahaean, L. P., Mukid, M. A., \& Wuryandari, T. (2014). Model Regresi Cox Proportional Hazard Pada Data Lama Studi Mahasiswa (Studi Kasus Di Fakultas Sains dan Matematika Universitas Diponegoro Semarang Mahasiswa Angkatan 2009). Jurnal Gaussian, 3(2), 173-181.

Kleinbaum, D. G., \& Klein, M. (2010). Survival Analysis (Vol. 3). Springer.

Moore, D. F. (2016). Applied survival analysis using R. Springer.

Rohmaniah, S. A., \& Danardono, D. (2016). Pemodelan Regresi Cox dan Regresi Weibull Waktu Sembuh Diare Pada Balita. Unisda Journal of Mathematics and Computer Science (UJMC), 2(1), 50-55.

Sudrajat, J., Rizki, S. W., \& Perdana, H. (2018). Perbandingan Model Regresi Parametrik Eksponensial dan Weibull Pada Data Survival Tersensor Interval. BIMASTER, 7(3).

Zhang, Z. (2016). Parametric regression model for survival data: Weibull regression model as an example. Annals of Translational Medicine, 4(24). 